\title{
Solitary plasmacytoma of clavicle: A case report
}

\author{
Aruj Dhyani, Abhash Shankar, Arunima Gupta, Rupesh Kumar, \\ Koushik Chatterjee, Anup Majumdar
}

\begin{abstract}
Introduction: Plasmacytoma is a localized collection of malignant plasma cells. The disease can be divided into solitary plasmacytoma of the bone (SPB) and extramedullary plasmacytoma (EMP), both of which are distinct entities. An EMP, the rarer of the two, has soft tissue infiltration by clonal plasma cells without any occult or systemic myeloma. Whereas, SPB has a solitary lytic bone lesion with infiltration of monoclonal plasma cells, with absence of the same on a random marrow sampling or any evidence of systemic myeloma. Though SPB may involve any bone in the body but involvement of medial end of clavicle, though reported, is extremely rare. Case Report: Herein, we report a case of a 65-year-old farmer presented with pain and swelling of the medial end of the left clavicle, which was postoperatively diagnosed to be a solitary plasmacytoma by virtue of histopathology and IHC, with no other evidence
\end{abstract}

Aruj Dhyani ${ }^{1}$, Abhash Shankar ${ }^{1}$, Arunima Gupta ${ }^{1}$, Rupesh Kumar $^{2}$, Koushik Chatterjee ${ }^{3}$, Anup Majumdar ${ }^{4}$

Affiliations: ${ }^{1} \mathrm{MBBS}$, Junior resident, Department of Radiotherapy, IPGME\&R/SSKM Hospital, Kolkata, West Bengal, India; ${ }^{2}$ MBBS, MS, MCh, Mch trainee, Department of CTVS, IPGME\&R/SSKM Hospital, Kolkata, West Bengal, India; ${ }^{3} \mathrm{MBBS}$, MD, Assistant professor, Department of Radiotherapy, IPGME\&R/SSKM Hospital, Kolkata, West Bengal, India; ${ }^{4} \mathrm{MBBS}, \mathrm{MD}$, Professor \& HOD, Department of Radiotherapy, IPGME\&R/SSKM Hospital, Kolkata, West Bengal, India.

Corresponding Author: Dr. Aruj Dhyani, Room No. 401 Junior Doctor's Hostel, IPGME\&R and SSKM Hospital, 242 A.J.C Bose Road, Kolkata- 700020, West Bengal, India; Ph: 08981600947; Email: drarujdhyani1@gmail.com

Received: 12 December 2013

Accepted: 17 January 2013

Published: 01 August 2013 of osteopenic lesions on radiographs, a negative bone scan, absence of marrow involvement by monoclonal plasma cells, presence of M-band on serum protien electrophoresis, in the IgG region and no evidence of anemia, hypercalcemia, hyperuricemia, hypercreatininemia, nephropathy, respiratory and urinary tract infections that can suggest the presence of any systemic myeloma. Conclusion: The case of solitary plasmacytoma of the clavicle reported here is a very rare as a disease entity, and rarest because of the site of involvement. The patient was treated with surgery and radiotherapy and had excellent disease control.

Keywords: Solitary plasmacytoma bone (SPB), Multiple myeloma, Clavicle, Extramedullary plasmacytoma

$$
* * * * * * * * *
$$

Dhyani A, Shankar A, Gupta A, Kumar R, Chatterjee K, Majumdar A. Solitary plasmacytoma of clavicle: A case report. International Journal of Case Reports and Images 2013;4(8):440-443.

$$
* * * * * * * * *
$$

doi:10.5348/ijcri-2013-08-351-CR-10

\section{INTRODUCTION}

Solitary plasmacytoma of the bone (SPB) comprises only $3-5 \%$ of all plasma cell neoplasms [1]. The new world health organization (WHO) criteria define SPB as a solitary lytic bone lesion with infiltration of monoclonal plasma cells, with absence of plasmacytosis on a random marrow sampling, with absence of any evidence of systemic myeloma (renal insufficiency/ anemia/hypercalcemia) and a negative bone scan; along 
with a monoclonal gammopathy on serum protein electrophoresis.

The SPB more commonly involves the axial skeleton, with an active marrow, as in vertebra, ribs, skull, pelvis, femur, clavicle and scapula relatively sparing the appendicaular skeleton [1].

Primary bone tumors and tumor-like lesions of clavicle are uncommon, comprising only $0.45 \%$ of the total, and their occurrence is more likely to be malignant, than benign $[2,3]$. We hereby present a case of SPB involving the clavicle, which is rare as per the disease entity and rarer because of the site involved.

\section{CASE REPORT}

A 65-year-old male farmer was presented with a twomonth history of swelling and a month old pain, increasing on exertion, around the left shoulder, with loss of appetite for the same duration. The lump was initially the size of a lemon, before it progressed. Clinical examination revealed a hard non-tender lump on the medial end of the left clavicle $4 \times 5 \mathrm{~cm}$ with restricted shoulder mobility. There were no palpable nodes. Radiographs of chest showed a lytic expansile lesion involving medial one-third of left clavicle associated with a soft tissue mass in the apical region of the chest (Figure 1).

A plain non-contrast computed tomography (CT) scan of the neck and thorax is shown in Figure 2.

(i) Normal CT scan of the neck,

(ii) Soft tissue density lesion with bony expansion and erosion of medial end of left clavicle with adjacent soft tissue density lesion and no evidence of rib crowding- bone biopsy suggested,

(iii) Fibrotic strands in both upper and right lower lobes.

(iv) Simple liver cyst.

Ultrasonography of the whole abdomen showed a simple cyst in right lobe of liver. Blood counts, liver and kidney function tests were normal except for serum LDH $725 \mathrm{U} / \mathrm{L}$. Bone marrow examination revealed anemia of chronic disease, with no evidence of plasmacytosis or secondary deposits.

Fine needle aspiration of the clavicular lump revealed a malignant mesenchymal neoplasm, possibly spindle cell sacoma with lymphoplasmacytic infiltration. Independent review of the slides too, did not reveal the presence of any abmormal or immature plasma cells, probably because of sampling error or error in terms of slide preparation or preservation (Figure 3). The patient then underwent an excision of the left clavicular lump. The postoperative histopathology showed the presence of a plasma cell neoplasm, comprising sheets of immature plasmacytoid cells, admixed with a few mature plasma cells (Figure 4). Immunohistochemistry (IHC) showed expression of CD 138 and $\mathrm{CD} 38$, and are immunonegativity for cytokeratin, CD 56 and CD 20, confirming the diagnosis to be of plasma cell neoplasm. The IHC for immunoglobulin light chain was not done.

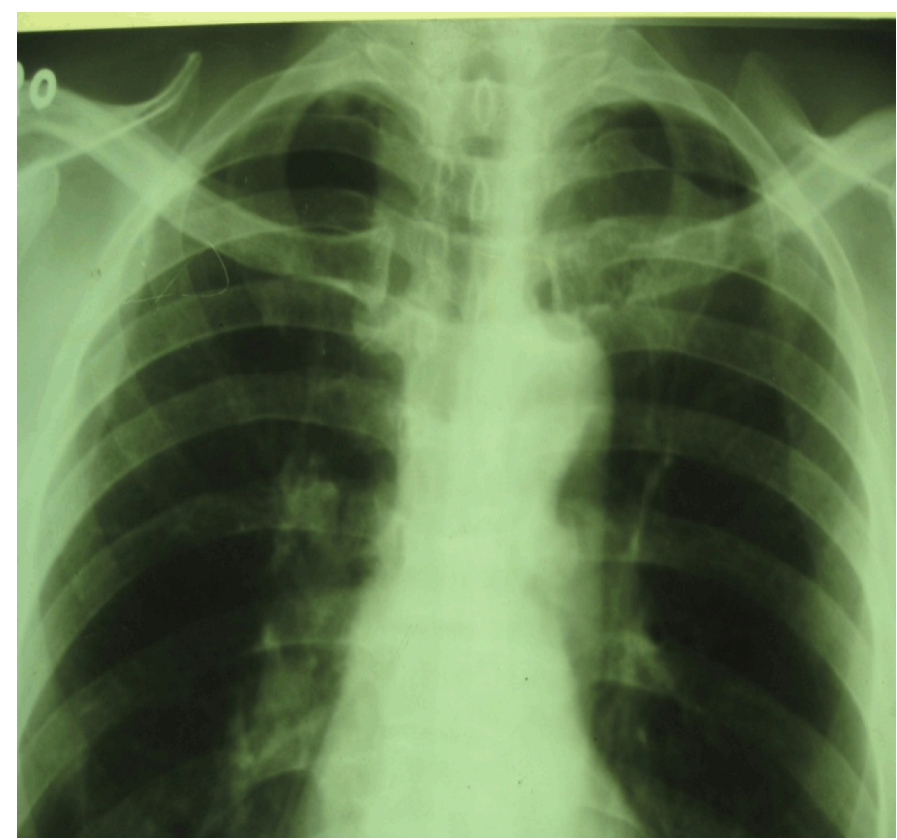

Figure 1: Radiograph of the left clavicle showing lytic expansile lesion involving medial end of the left clavicle associated with a soft tissue mass in the apical region of the chest.

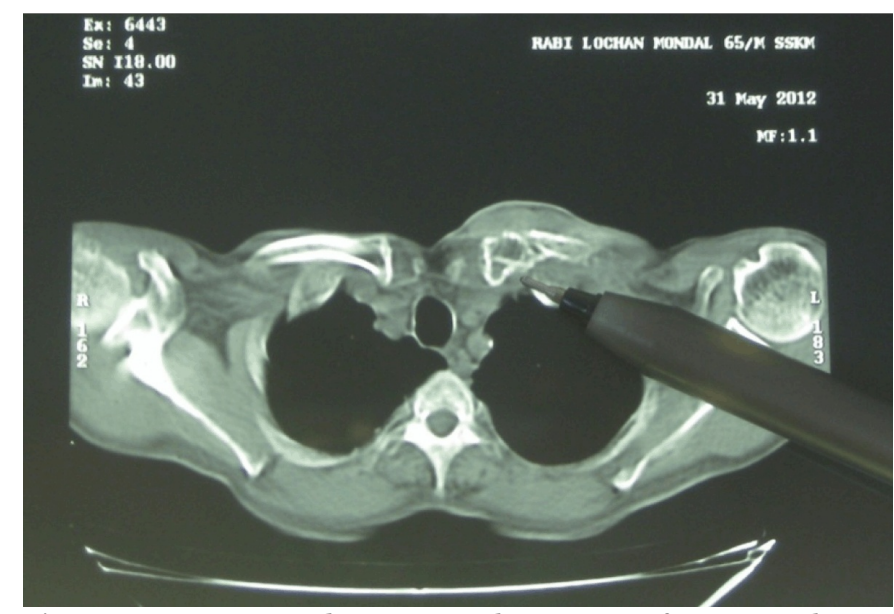

Figure 2: Computed tomography scan of upper thorax showing an expansile lytic lesion in the medial end of the left clavicle.

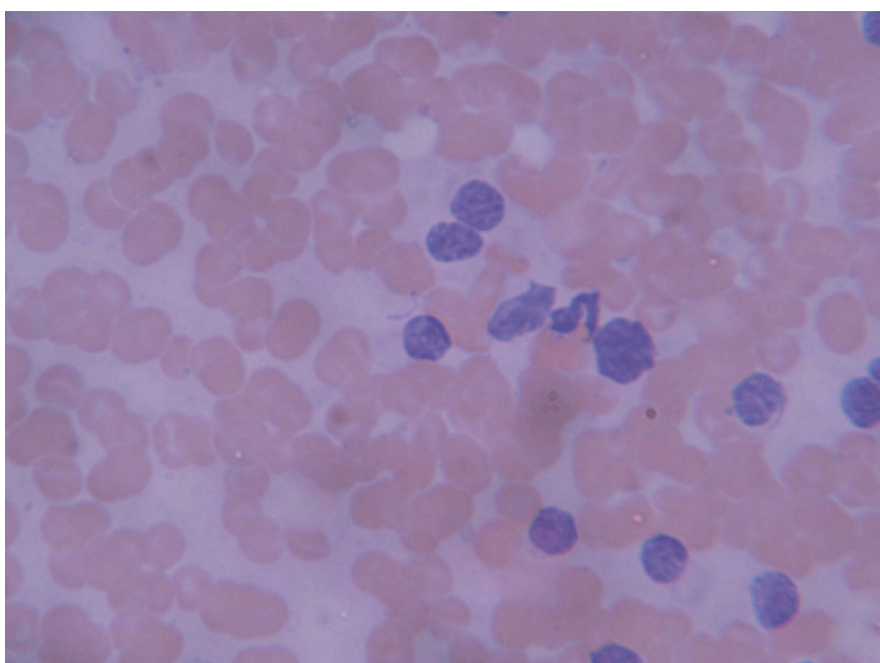

Figure 3: Features suggestive of malignant mesenchymal neoplasm, possibly spindle cell sacoma with lymphoplasmacytic infiltration. 


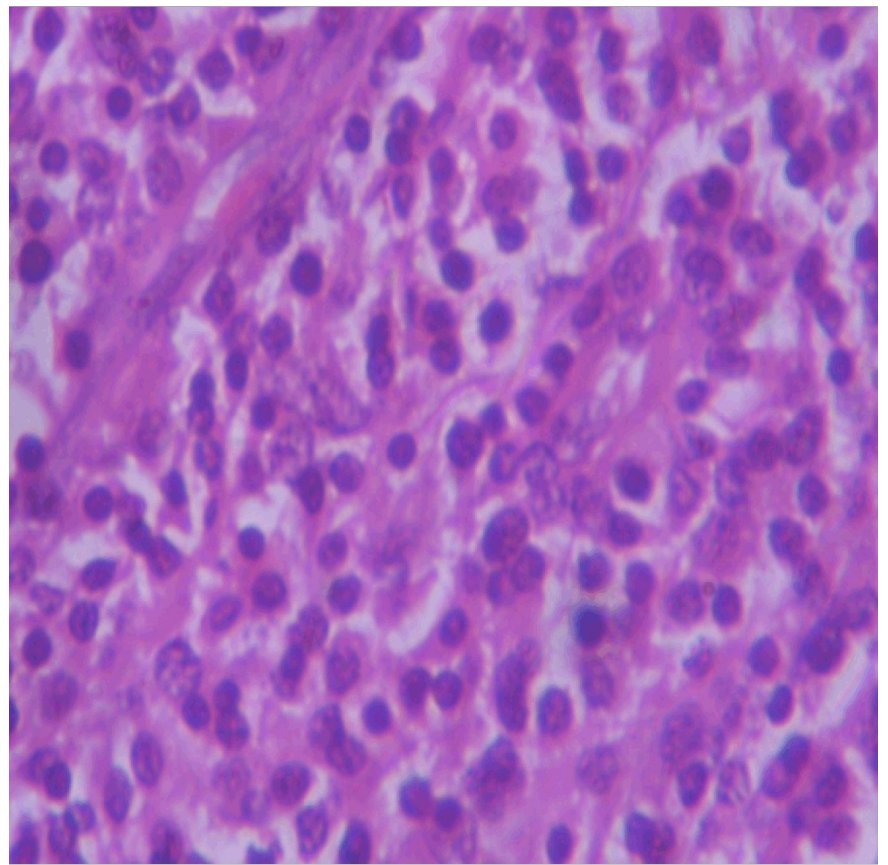

Figure 4: Microscopic examination showing tumor composed of sheets of immature plasmacytoid cells with mature plasma cell also present.

Serum protein electrophoresis showed the evidence of monoclonal gammopathy in the IgG region. There was no Bence Jones protien in urine. Serum calcium was $9.2 \mathrm{mg} / \mathrm{dL}$ with albumin $3.8 \mathrm{~g} / \mathrm{L}$, X-rays revealed no evidence of any other lytic bone lesions, the whole body bone scan was negative, and no evidence of urinary tract or respiratory tract infections.

This patient was then treated with postoperative radiotherapy. At the third month of follow-up the patient is doing well with almost full range of movement at left shoulder joint and normal daily activities.

\section{DISCUSSION}

Primary bone tumors and tumor-like lesions of clavicle are uncommon. Klein et al. presented a series of around 1300 primary bone tumors and found that only $0.45 \%$ of them involved the clavicle [2]. In a review of 35 primary bone tumors of the clavicle that have been treated at the Memorial Sloan-Ketterin cancer centre, Smith et al. reported only five benign lesions [3]. Primary bone tumors of the clavicle are therefore more likely to be malignant than benign. Solitary plasmacytoma of the bone accounts for $10-30 \%$ of primary chest wall malignancies. They are more common in male patients and usually occur at mean age of 60 years or later. The most common chest wall location is ribs, clavicle, sternum [4]. Considerable debate exists regarding the relationship of SPB and EMP to multiple myeloma. Most authors believe that SPB is simply an early presentation of multiple myeloma whereas others consider that SPB is a clinically distinct entity [5].
As far as treatment is concerned excision remains the mainstay of treatment, where ever possible. Radiotherapy has also shown to be successful for local control of solitary plasmacytoma [6]. However, chemotherapy is recommended to patients with disseminated disease and evidence of progression following the primary modes of treatment. This case is extremely rare, and the patient had an excellent disease control with surgery and radiotherapy. Long-term follow-up will be necessary for our patient as $35-55 \%$ of patients of SPB, might end up developing multiple myeloma over a period of 10-12 years from initial diagnosis [7].

\section{CONCLUSION}

We reported a case of solitary plasmacytoma of clavicle which is a rare disease, presenting in an extremely rare site. The diagnosis was confirmed by clinical suspicion, postoperative biopsy, immunohistochemistry, and other investigations relevant to rule out the presence of systemic myeloma. The patient was treated by surgery followed by radiotherapy. As per world literature this is the standard of care. The patient had excellent disease control, and is currently undergoing follow-up.

$$
* * * * * * * * *
$$

\section{Author Contributions}

Aruj Dhyani - Conception and design, Drafting the article, Final approval of the version to be published Abhash Shankar - Analysis and interpretation of data, Drafting the article, Final approval of the version to be published

Arunima Gupta - Acquisition of data, Critical revision of the article, Final approval of the version to be published Rupesh Kumar - Acquisition of data, Critical revision of the article, Final approval of the version to be published Koushik Chatterjee - Conception and design, Critical revision of the article, Final approval of the version to be published

Anup Majumdar - Analysis and interpretation of data, Critical revision of the article, Final approval of the version to be published

\section{Guarantor}

The corresponding author is the guarantor of submission.

\section{Conflict of Interest}

Authors declare no conflict of interest.

\section{Copyright}

(C) Aruj Dhyani et al. 2013; This article is distributed under the terms of Creative Commons attribution 3.0 License which permits unrestricted use, distribution and reproduction in any means provided the original authors and original publisher are properly credited. (Please see 
www.ijcasereportsandimages.com/copyright-policy.php for more information.)

\section{REFERENCES}

1. Jaffe ES, Harris NL, Stein H, Vardiman JW (editors). World Health Organization Classification of Tumours. Pathology and Genetics of Tumours of the Haematopoietic and Lymphoid Tissues. IARC Press: Lyon 2001.

2. Küppers R, Klein U, Hansmann ML, Rajewsky K. Cellular origin of human B-cell lymphomas. N Engl J Med 1999;341(20):1520-9.

3. Smith J, Yuppa F, Watson RC. Primary tumor and tumor-like lesion of clavicle. Skeletal Radiol 1988;17(4):235-46.
4. Graeber GM, Jones DR, Pairolero PC. Primary neoplasms. In: Pearson FG, Ginsberg RJ; eds. Thoracic Surgery. 2nd ed. Philadelphia: Churchill Livingstone, 2002:1422.

5. Shih LY, Dunn P, Leung WM, Chen WJ, Wang PN. Localised plasmacytomas in Taiwan: comparison between extramedullary plasmacytoma and solitary plasmacytoma of bone. $\mathrm{Br} \mathrm{J}$ Cancer 1995;71(1):128-33.

6. Mill WB, Griffith R. The role of radiation theraphy in the management of plasma cell tumors. Cancer 1980;45(4):647-52.

7. Meis JM, Butler JJ, Osborne BM, Ordóñez NG. Solitary plasmacytomas of the bone and extramedullary plasmacytomas. A clinicopathologic and immunohistochemical study. Cancer 1987;59(8):1475-85.
Access full text article on other devices

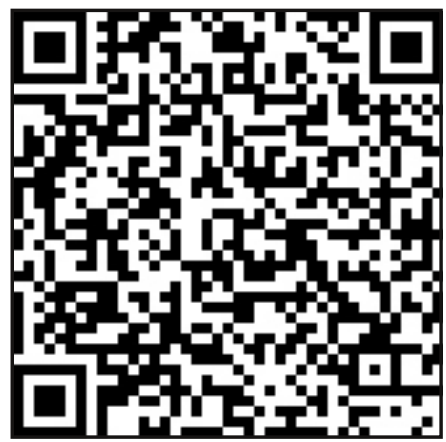

Access PDF of article on other devices

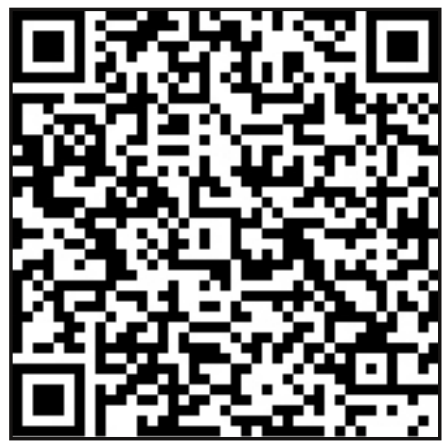

